\title{
Subjetividade, linguagem e criação: uma porposição possível entre escrita e sinthome
}

\author{
Margareth Schäffer
}

RESUMO: This article seeks to analyze the lacanian course of sinthome, signifier and letter, aiming at articulating a theoretical frame to the analysis of the statute of the signifier and the letter in the process of subjectivity of children and adolescents in school age.

PALAVRAS-CHAVE: Subjetividade; Linguagem; Criação; Escrita; Sinthome.

\section{INTRODUÇÃO}

Na contemporaneidade, as questões de subjetividade entrelaçam-se, de forma bastante estreita, com a linguagem e a criação. A linguagem enquanto um meio de subjetivação que propicia singularidades, formas de criação para o sujeito instituir-se. Nesse sentido, este artigo busca incidir sua investigação justamente sobre estas produções de subjetividades, procurando produzir algumas reflexões teóricas acerca das psicoses para podermos pensar na constituição da subjetividade de crianças e adolescentes no universo específico da realidade escolar. Assim, através da escrita de crianças e adolescentes, perguntamo-nos quais subjetividades a escola está produzindo, entendendo-se a escola, aqui, como um lugar social e cultural de produção e criação de subjetividades. Nossas pesquisas anteriores, realizadas através de dois programas de pesquisa - Subjetividade e Linguagem $^{I}$ e Psi-

Margareth Schäffer é professora titular de Psicologia da Educação da Faculdade de Educação da Universidade Federal do Rio Grande do Sul. Pesquisadora do CNPq.

' Programa Subjetividade e Linguagem, com as seguintes pesquisas vinculadas (Bolsa IC CNPq): As impossibilidades e negaçôes atribuidas aos sujeitos, tanto na escola, como na literatura especializada (1998-1999); O problema de aprendizagem segundo os protocolos de encaminhamentos da escola à clínica (1999-2000); Encaminhamentos da clínica acerca da demanda escolar sobre a "não-aprendizagem" (2000-2001); As histórias que as crianças contam sobre o nào-aprender (2001-2002); A produção da escrita na escola de crianças e adolescentes com ou sem estruturação psicótica (2002-2003). 
canálise e Lingüística ${ }^{2}$ - também tinham por objètivo uma análise das subjetividades; entretanto, as subjetividades eram aquelas que diziam respeito a uma forma subjetiva muito singular - sujeitos em estruturação psicótica e/ou com problemas de aprendizagem. Para análise de tais subjetividades, nos amparamos nas teorias psicanalíticas e as do campo da linguagem, principalmente as produções que diziam respeito às psicoses. Nessas análises teóricas e do campo empírico, nos deparamos com questões de subjetividade que ultrapassam o campo das classificações "patológicas" ou de problemas de aprendizagem. Tais estudos demonstraram que não podemos atrelar a constituição da subjetividade a um campo prévio de nominação, sob o risco de perder-se o sujeito que aí está se constituindo. Mesmo que seja nas psicoses, sempre há sujeito e processos de subjetivação, singulares que sejam. Aliás, toda a constituição subjetiva do humano é singular e comporta aspectos de criação para além dos modelos sociais e culturais oferecidos. É esse traço de criação, de singularidade subjacente aos processos de subjetivação que nos fazem trabalhar com as crianças e adolescentes nas escolas, sem a marca específica de alguma "patologia" ou problema. Os estudos de Jacques Lacan, acerca das psicoses, principalmente os seus últimos escritos, nos fornecem subsídios importantes para pensarmos a constituição de subjetividades para além das psicoses. Tais estudos teóricos serão discutidos neste artigo, de forma a sustentar a questão que nos envolve, qual seja: O estatuto do significante e da letra na produção escrita de crianças $e$ adolescentes em processo de escolarização, procurando articular tais producões na sua visibilidade pública e social, cujas conseqüencias produziriam um efeito subjetivador de criação.

Para refletir sobre a questão acima enunciada, faremos um percurso teórico de forma a elaborar um quadro de análise, o qual permita situarmos alguns encaminhamerntos possíveis para tal questão. Não realizaremos nenhuma análise empírica, apenas procuraremos apontar uma via possível de análise para tais produções.

Para analisar as relações entre o significante e a letra nas produções escritas de crianças e adolescentes em processo de escolarização nos fundamentamos teoricamente a partir de três perspectivas, quais sejam: do ponto de vista da psicanálise, da educação como campo empírico e da lingua-

${ }^{2}$ As pesquisas anteriores, financiadas pelo $\mathrm{CNPq}$ (produtividade e IC), são: “A constituição ${ }^{2}$ As pesquisas anteriores, financiadas pelo CNPq (produtividade e
da subjetividade: o papel do significante na neurose e na psicose" (2000-2002); “A constituiçãa da subjetividade: a metáfora na neurose e na psicose (concluída em julho/2000) e "A construção da subjetividade: marcas lingüísticas no discurso do neurótico e do psicótico" (Concluída em julho/98). gem. A necessidade de tal análise tem sua origem nas constatações de pesquisas anteriores realizadas por mim e pelo meu grupo de pesquisa, as quais dizem respeito à especificidade do significante e da letra nas psicoses, quer em estruturação - crianças e adolescentes -, quer em adultos. O estudo de tais especificidades aponta que a relação entre as produções escritas destes sujeitos e sua "publicização" no universo escolar e cultural parece produzir um efeito subjetivador e estabilizador de sua estruturação psíquica. Nesse sentido, nossos dados empíricos e consequientes análises teóricas nos forneceram subsídios para ampliar o escopo das pesquisas anteriormente realizadas procurando, agora, atingir um duplo objetivo: por um lado, verificar qual o estatuto do significante e da letra nas escritas de crianças/adolescentes e, por outro lado, articular tais produções na sua visibilidade pública e social, cujas conseqüências produziriam um efeito subjetivador de criação (através da realização de oficinas, entre outros). Tais análises não incidem sobre alguma "patologia" específica - psicoses, problemas de aprendizagem - mas, sim, sobre os processos de subjetivação dos sujeitos, na sua face articuladora entre escrita e criação. Tal avanço acompanha os avanços realizados por Lacan no estudo sobre as psicoses, principalmente no que diz respeito a passagem do sintoma ao sinthome.

\section{ANTECEDENTES TEÓRICOS}

Na pesquisa sobre o significante (SCHÄFFER et alli, 2002), acentuamos as diferenças que existem entre a estrutura neurótica e a estrutura psicótica. Observávamos, ainda, que tais distinções só puderam ser feitas por Lacan graças à noção de significante, a qual pressupõe uma ordem de sentido aquém do mundo. Assim, a teoria do significante permitiu responder à questão da loucura de um modo inteiramente novo, já que o psicótico de forma alguma está fora do sentido, embora esteja fora do significado. Em consequiência, tanto para a área clínica, como para a área escolar, não se trata de um processo de "compreender o louco", mas de analisar o modo como o sentido aí é articulado.

Em outros termos, na psicose, mesmo que exista "percalços" no processo de amarragem dos significantes, há sujeito; são esses "percalços" que constituíram o foco de interesse da pesquisa sobre o significante. Nesse sentido, propusemos a relação entre significante e metalinguagem, através da discussão sobre a lógica do significante e, a partir desse percurso, buscamos abordar tal relação, especialmente, no que diz respeito ao discurso ( $\mathrm{e}$ sua enunciação) do psicótico.

Em vista deste percurso e das análises realizadas na pesquisa sobre o 
significante, afirmamos que, no discurso do psicótico, o sentido articula-se de forma diferencial. Assim, onde o sentido deveria instaurar-se em virtude da sua condição de não-Um (heterogeneidade constitutiva), constatamos apenas o sentido como Um. Verificamos, naquela pesquisa, que o paciente, ao ser interpelado pelo entrevistador, não reconhecia a demanda de especificação de sentido, limitando-se à mera repetição do segmento lingüístico. Entretanto, já na análise de outro segmento de discurso, do mesmo paciente, as demandas de especificação de sentido do entrevistador encaminharam, também, para uma espécie de "culminância" de tentativa de obturar o sentido. Vale lembrar que falamos em "tentativa" de obturar o sentido, para sublinhar um movimento de instauração da subjetividade, pelo psicótico. Isso eqüivale a dizer que na psicose o sujeito não está fora do sentido, apesar dos "percalços" que este enfrenta na sua articulação.

Santos, ao discutir a reinvenção lacaniana das estruturas freudianas da psicose, comenta que muitos autores afirmam que o psicótico estaria fora da linguagem, o que acreditamos ser um engano. Com relação a isso, confunde-se exclusão do mito edípico com exclusão do campo da linguagem. Essa afirmação corrobora, de certa forma, o que afirmamos anteriormente em relação às análises por nós desenvolvidas, ou seja: o psicótico não está fora do sentido, apesar da sua articulação diferencial. Para a autora, temos que repensar a psicose distinguindo corretamente a falta (na estrutura da linguagem) de seu mito (a falta edípica) (SANTOS, 1999, p. 47). Assim, a experiência do inconsciente na psicose e seu laço com os fenômenos elementares (o neologismo e a fala interrompida) são a via régia para o aprofundamento da dimensão da falta, do significante vazio de significado, revelando o verdadeiro referente da linguagem, o objeto a (idem).

Alicerçados em tais considerações podemos dizer que, do ponto de vista da estrutura da linguagem, há uma literalização, ou seja, que no fio do discurso há uma sutura da cadeia discursiva. O psicótico parece tomar as palavras como coisas, tornando-as literais, o que não significa que este não faça metáforas, por exemplo. Tomar as palavras como as próprias coisas não é o contrário de operar metaforicamente na linguagem (idem, p. 62). Tal acontecimento, na psicanálise, remete à foraclusão do Nome-do-Pai. Da mesma forma que literalizar não significa estar impedido de fazer metáforas, falar em foraclusão do Nome-do-Pai não significa dizer que, por falta de um significante - Nome-do-Pai -, haja ausência radical de simbolização do desejo por meio da metáfora paterna (idem, p. 56) e, por conseqüência, o sujeito esteja totalmente fora do sentido. Assim, na pesquisa sobre o significante nas psicoses, o que verificamos foi uma articulação diferencial do sentido e não sua ausência radical. Da mesma forma, em termos da foraclusão do
Nome-do-Pai, podemos dizer que o que está foracluído não é o elemento do movimento mas, sim, sua dinâmica.

Para Birman, a foraclusão do significante Nome-do-Pai e a foraclusão como tal são duas coisas distintas. Assim, a foraclusão dos significantes (...) existe em todos os sujeitos no sentido de que ela é um processo inerente à linguagem. (...) na linguagem, sempre permanecerá um indizivel último que assim justifica a foraclusão (BIRMAN, 1999, p. 83). Em compensação, quando essa foraclusão diz respeito a este significante particular que é o significante do Nome-do-Pai, isso éa marca específica de um processo indutor psicotizante (idem). A ausência desse significante impede a amarração das articulações do discurso, do sentido, levando o sujeito, muitas vezes, a uma deriva delirante, a uma proliferação de sentidos. Verificamos, assim, que a cadeia significante falta ao sujeito. Enfim, é como se o sujeito, na constituição acidentada de sua subjetividade, estivesse no discurso, na linguagem, mas ignorando o rumo das articulações da mesma.

De certo modo, nossas análises sobre o significante no discurso do psicótico, nos permitiram discutir, em outras bases, o estatuto da linguagem, do significante e da letra nas psicoses. Entretanto, não é só um estudo da linguagem em si mesma; pelo contrário, é um estudo que acompanha o avanço lacaniano sobre a questão das psicoses, tal como será discutido por nós, nas próximas seções. Esse estudo acompanha as modificações que a teoria do significante sofreu na elaboração lacaniana, ou seja: uma coisa é o significante do período "retorno a Freud"; outra, o significante da "lógica do significante", que tomou corpo a partir dos anos 1960 (BIRMAN, 1999, p. 76).

A lógica do significante, onde este não significa nada - o inconsciente como pura articulação significante - nos remete, portanto, às relações deste com a letra, ou seja, à redução do referente à letra, ao significante puro, evidenciando sua relação ao vazio das origens que ele insiste em incluir, em representar (idem, p. 72). Para Birman, a letra é um significante que se repete, mas que não representa o sujeito para outro significante, escapando, assim, à regra de que nenhum significante pode significar-se sozinho.

No lugar do vazio, da Coisa, Lacan coloca a letra, ou seja, o significante na condição de localizado: a letra, radicalmente é efeito do discurso (LACAN, 1975 , p. 36). O exemplo dado por Lacan é Joyce, pois este abandona o significante para ir ao encontro da letra. Assim,

é pelo fato de os significantes se encaixarem uns com os outros, se comporem, se entrechocarem - leiam Finnegan's Wake - que se produz alguma coisa que, como significado, pode parecer enigmático, mas que é realmente o que há de mais próximo ao que nós analistas, graças ao discurso analítico, temos de ler: o lapso (idem, p.37). 
Para alguns autores como Regnault, tal situação significa um abandono do campo da interpretação, do significante, para o exercício da letra da escrita (REGNAULT, 2001, p. 33). Também Paoli, ao comentar o modo como Lacan trata o uso que Joyce fazia da língua na literatura (Seminário XXIII - Le Sinthome), diz que se a Lingüística busca um saber acerca do significante a partir de lalangue, Joyce, a partir desta, extrai um significante que não é lingüistico - translingüistico, na medida em que é uma mescla de línguas -e desdobra a linguagem até sua própria destruição (PAOLI, 2001, p. 28).

$\mathrm{Na}$ contramão de tal posição, acreditamos que a passagem do significante à letra não significa um abandono do primeiro e, sim, um redimensionamento do lugar do significante na teoria e na prática clínicas. No nosso entendimento, com a questão do sinthome, Lacan introduziu, além de outras contribuições, o enigma da equivocação translingüística, onde aparece uma forma específica de manejar a letra. Soler, ao falar sobre esta forma de manejar a letra, salienta que não se trata somente de uma questão literária mas, sim, de uma problemática especificamente analítica. Perguntamo-nos, assim, se Lacan, ao recorrer à literatura para estabelecer a problemática do sinthome, abandona seu recurso ao significante e, por conseqüência, os estudos lingüísticos, tal como crê Paoli (2001). Valemonos de Soler (idem) para responder a questão. A autora diz que o recurso de Lacan à literatura segue estritamente seu recurso à lingüística. Assim, a lingüística consigna o 'material' da análise, e até mesmo o 'dispositivo como qual se opera na análise', que não é nada além das assertivas proferidas pelo analisante e pelo analista (SOLER, 1998, p. 15).

Assinalamos, assim, que não há abandono da teoria do significante, mas um redimensionamento do mesmo, em função das produções lacanianas a partir dos anos sessenta e setenta. Tal redimensionamento abre para inúmeros questionamentos teóricos e clínicos extrapolando, inclusive, a dimensão da clínica. Dentre estes, podemos citar as relações que o significante mantém com a letra, ou seja, o modo como o significante se faz letra. Allouch, ao comentar que toda formação do inconsciente é um hieróglifo, pergunta:

no sentido inicial que resiste à compreensão imediata, não é transparente e só se deixa ler mediante um trabalho de deciframento. Mas se este trabalho reclama associação livre, convoca, com razão, a fala do analisando, o que é que liga uma à outra? (ALLOUCH, 1995, p. 17).

O autor responde, dizendo que, em Lacan, tal questão é a da relação entre o significante e a letra (idem). E, é nessa direção - a relação entre o significante e a letra, escrita e criação - que pensamos conduzir as nossas próximas reflexões.

\section{FUNDAMENTAÇ̃̃O TEÓRICA}

Tal como apontado nos resultados de nossa pesquisa sobre o significante, bem como de nossa pesquisa sobre as crianças/adolescentes em estruturação psicótica na escola ou com problemas de aprendizagem, faz-se necessário entendermos como acontece a estruturação subjetiva do sujeito, dependente que é do estabelecimento da relação entre o significante e a letra. Nesse sentido, pretendemos expor, a partir desse momento, algumas considerações sobre o modo como o significante e a letra são articulados nas psicoses, acompanhando o avanço lacaniano nessa área para, então, extrapolar tais considerações para o estudo das questões de subjetividade de crianças e adolescentes em processo de escolarização.

\subsection{As relações entre o significante e a letra nas psicoses: abordagem psicanalítica}

Na pesquisa acerca do significante ${ }^{3}$, destacamos que no psicótico a função organizadora do Nome-do-Pai é foracluída, mas não os significantes relativos a esta função. Salientávamos, ainda, que os significantes edípicos e paternos estão em algum lugar no saber psicótico, mas organizados de outra forma, o que implica dizer que nas psicoses há sujeito, apesar dos "percalços" que este enfrenta na amarragem dos significantes. São esses "percalços" da amarragem, do sujeito, que constituíram o foco de nosso interesse. Assim, procuramos explicitar, ao longo de tal pesquisa, o modo como a lingüística entende a noção de significante, bem como as articulações possíveis entre os conceitos lingüístico e psicanalítico de significante.

Julgamos, a partir disso, que algumas questões permaneceram em aberto, principalmente no que diz respeito ao hiato existente entre as primeiras posições de Lacan acerca do Nome-do-Pai e àquelas onde ele se interroga sobre o nó borromeano, quando ele fala, no plural, em nomes do pai. Esse hiato entre as primeiras elaborações topológicas e as do nó borromeano

${ }^{3}$ A questão do significante. In: SCHÄFFER, Margareth; FLORES, Valdir do Nascimento; BARBISAN, Leci (ORG.). Aventuras do sentido: psicanálise e Lingüistica. Porto Alegre: EDIPUC, 2002. 
diz do movimento de retorno de Lacan às noções freudianas. Salienta-se, entretanto, que isso não significa o desaparecimento das elaborações em torno do Nome-do-Pai; elas são reelaboradas de outro modo. Assim, é certo que a cadeia significante é organizada pelo Nome-do-pai, mas há uma nova formulação em torno da palavra cadeia - a cadeia borromeana. Isso significa que há, também, outra concepção de linguagem - que não é tomada somente como relação entre código e mensagem ou sistema de comunicaç̃ão $0^{4}$ a linguagem como criação. Voltaremos a esta questão no final deste item.

A quarta consistência de um nó borromeano é ${ }^{5}$, assim, a do Nome-doPai. Para Porge, a grande novidade do R.S.I. reside no novo sentido de Nomedo-Pai, onde este termo não designa apenas o nome dado ao pai, mas ao nome dado pelo pai - o pai como nomeante. Assim,

não somente o nó borromeano inclui na problemática do Nomedo-Pai a contribuição sintomática de Freud, o complexo de Édipo, mas transforma esta problemática do Nome-do-pai, e porque real, simbólico e imaginário são qualificados de nomes do pai é permitido concluir que o nó borromeano em si constitui para Lacan um novo Nome-do-Pai (PORGE, 1998, p. 161).

Assinale-se, ainda, que com o nó o real encontra seu estatuto. No seminário R.S.I (1975), Lacan designa o que corresponderia, em Freud, a categoria do real - o oculto. Para Allouch, hoje, enfim, ousa-se começar a abordar a questão do oculto em Freud (idem, p. 264).

Com a topologia nodal, Lacan reelabora a questão da psicose. No Seminário sobre o Sinthoma (1975-1976), onde o Nome-do-Pai é assimilado à consistência do symptôme, temos um movimento de introdução a uma quarta consistência, amarragem sobre um modo borromeano R.S.I., sendo que a foraclusão pode ser evocada sobre o modo de carência dessa quarta consistência. Na década de 70, os exercícios topológicos, onde cada nó re-

4 Freire, ao tecer considerações sobre a letra e a psicose, aborda o que está além da representação. Baseando-se em Lacan, a autora afirma que a estrutura deve ser definida não apenas tação. Baseando-se em Lacan, a autora afirma que a estrutura deve ser definida não apenas através do campo simbólico (e imaginário), mas também com o impossivel de representar, o real (1999, p. 572). Para reafirmar esta posição de Freire, encontramos no éditorial da revista Le discours Psychanalytique, a seguinte afirmação: On pourra dire les deux choses: certes, la chaîne signifiante est centrée et organisée par le nom du père, mais il faut tenir aussi, en même temps mais d'un autre mouvement qui n'est pas en continuité, que c'est le caractère borroméen du nouage de la chaîne R.S.I (Qui n'est pas la chaine à proprement parler signifiante) Qui rend compte du caractère opératoire du nom du père à certains points de la chaîne signifiante, (ce Qui

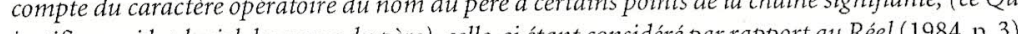
justifie aussi le pluriel des noms du père), celle-ci étant consideré par rapport au Réel (1984, p.3). ${ }^{5} \mathrm{Na}$ segunda sessão do seminário intitulado R.S.I, Lacan introduz o nó borromeano de quatro aros de barbante. Esta invenção da cifração nodológica diz respeito ao retorno a Freud. presenta um elemento da trilogia R.S.I, passaram a ocupar lugar decisivo no ensino lacaniano. Para Roudinesco, foi em 1975 que Lacan acrescentou ao trípto uma quarta volta, para a qual cunhou uma palavra-valise, santhomem' [sinthome, combinando symptôme e homme, além de aludir a saint] (ROUDINESCO, 1998, p. 541). Foi em homenagem a James Joyce que Lacan criou a quarta volta, designando-o por seu sintoma, isto é, por sua teoria da criação, a "epifania" ou êxtase místico, retirada de S. Tomás ("santo homem") (Idem). Com a questão do sinthome, é introduzido, também, o enigma da equivocação translingüística, onde aparece uma forma específica de manejar a letra, tal como já assinalado por nós anteriormente.

Recorrer à literatura implica, entre outras possibilidades, uma pergunta sobre como o uso literário da linguagem pode ser denominado um sintoma. Soler, ao comentar as relações entre criação literária e psicanálise, indica alguns caminhos. Assim, a criação literária pode ser um sintoma porque o sintoma é por si só uma invenção. O que significa criar? A resposta é: trazer algo à luz lá onde antes não havia nada (Idem). A invenção, pois, não é a criação; o sintoma inventa e a criação, a verdadeira criação, produz uma novidade radical - é um sintoma, ela o é em especial, e poderíamos dizer que $o$ artista/criador está sempre sem pai (Idem, p. 18). A autora faz uma comparação entre Joyce e Rousseau, procurando compreender, assim, as afinidades entre estrutura psicótica e criação, tal como Lacan o fez no Seminário, livro 23 (1975-1976), ao analisar o sinthoma em Joyce.

Para Lacan, a escrita de Joyce preenche uma função de sintoma; a letra está desconectada do Outro e dos efeitos de comunicação. Entretanto, salienta Soler, Rousseau não apresenta uma escrita sintoma, pois onde o Nomedo-pai falha, ele tentou fabricar suplências simbólicas. A autora salienta que onde Joyce foi bem sucedido - publicando seus escritos - Rousseau fracassa, pois o que ele foraclui the retorna de fora: ele fracassa não em fazer uma obra, mas em tratar sua paranóia através de sua obra (Idem, p. 27)

Vemos, pois, colocada a questão do significante foracluído, da letra como suplência, ou seja, a criação como um sintoma em especial. Lacan estabelece, assim, as afinidades entre psicose e criação artística (notadamente literária), para dizer que a psicose não é simples déficit e desordem. Para destacar a relação entre foraclusão de um significante primordial e a criação, Soler contrapõe o hermetismo de Joyce (trombetear a verdade) ao tudo dizer de Rousseau (transparência). Assim,

Pode-se, com efeito, conceber que a falha do simbólico que a foraclusão descobre se traduza, de um lado, em efeitos desorganizadores designados com o termo 'perda da realidade', mas que, por outro, funcione com um starter para produções inéditas. 
Flas nem sempre chegam até o sumo da arte, mas todas são o traço de que a foraclusão libera um efeito que podemos chamar de 'empucho à criação'. Lacan reconhece em Joyce aquele que levou este empuxo até seu limite identificável, até a função do sintoma, uma vez que dá o salto do simbólico ao real. Joyce artesão de si mesmo, tanto de seu nome como de sua saúde, se converte com Finnegans Wake em senhor da letra, se quisermos, o demiurgo de uma linguagem sem Outro, de uma arte inteiramente neológica ltação de unozo estranho e fora do sentido. Não há dúvida de que Rousseau ilustra um caminho diferente, ele que foi causa de tanta paixão (Idem, p. 30)

Eis uma longa citação que se justifica pela singularidade com que a autora retoma a questão do sinthoma (Lacan) nas psicoses. Resta, pois, perguntar, como podemos pensar o significante na sua relação à letra, já que, pelo menos em Joyce, vemos atacada não somente a sintaxe de uma língua, mas o um do significante. Recorrendo a Lacan (1975-1976), temos uma via a ser percorrida no que concerne à especificidade do significante. Para Lacan, no sintoma, o significante é casado com algo mais, encontrando-se, portanto, transformado. Esse algo mais é, para Soler, o gozo. Assim,

investir um termo, um significante, o qual é subtraído da substituição significante, da incessante cifra do gozo inconsciente, transforma-o em uma letra que é fora do significado e portanto real, uma letra que sozinha é capaz de fixar ou amarrar o próprio ser do gozo. É por isso que Lacan diz que o significante retorna na experiência como uma letra (Idem, p. 17).

No caso de Joyce, o que acontece é que entre sua escrita e seu público (porque Joyce publica) se estabelece um equivalente da cadeia significante, um efeito de comunicação.

As questões em aberto que assinalamos acima, tanto no que concerne à obra lacaniana, como no que concerne ao próprio estatuto do significante nesta obra - da cadeia significante à cadeia borromeneana -, devem-se, fundamentalmente, a um modo diferencial de tomada das questões acerca das psicoses, ou seja: temos o Seminário III, As Psicoses, e temos o Seminário XVIII, Le Sinthome, representando cada um, respectivamente, um momento crucial da elaboração lacaniana. Acreditamos, assim, que a análise do movimento que se dá entre uma formulação e outra, pode ser uma via interessante para estabelecermos as relações entre Nome-do-Pai/ significante/Sinthome, esclarecendo-nos, principalmente, as afinidades entre estrutura subjetiva e criação, significante e letra.
Estaria a criação, no psicótico, fora do sentido, pura matéria da letra, tal como em Joyce? Não podemos esquecer, entretanto, que Joyce construiu um canal (efeito) de comunicação entre ele e o mundo através de sua escrita. Assim, pergunta-se: qual a possibilidade de construção/criação para aqueles que não podem fazer de seu sintoma uma obra reconhecidamente notória? Parece-nos que a possibilidade de invenção/criação não pode ser atrelada somente ao seu produto "notório"; o sujeito, ao ser confrontado com uma posição ética, deve ser capaz de sustentar o rigor das fabricações da língua que ele opera. Para Brancion, Joyce não era louco, porque era artista. Assim, esse passo de Lacan na função do sinthoma traz um elemento absolutamente novo à clínica psicanalítica da psicose, operando uma distinção entre aquele que não é louco, porque pôde compensar pelo achado de um artifício especial a particularidade de seu caso, e aquele que se voltou para a psicose (BRANCION, 1996, p. 169). A invenção, a criação de um artifício especial, um savoir-faire, uma escrita, um artesanato; formas de fazer com o sinthoma. Uma resposta possível à questão acima enunciada.

No que diz respeito à especificidade da relação entre significante e letra anunciada anteriormente, acreditamos que é necessário ampliar a discussão existente. Tal ampliação diz respeito, fundamentalmente, à contribuição que tais estudos possam trazer para a abordagem dos fenômenos de linguagem nos processos de subjetivação de crianças/adolescentes e, por consequiência, para a questão do trabalho clínico e escolar. Nesse sentido, procuramos anunciar, na seção seguinte, como pensamos encaminhar tais estudos a partir do ponto de vista da psicanálise. Posteriormente, pretendemos assinalar alguns pontos acerca da relação entre o significante e a letra a partir dos estudos de linguagem, enquanto que nos encaminhamentos pretendemos retirar algumas reflexões para o trabalho com esses sujeitos na escola.

\subsection{Um percurso possível}

A reflexão a seguir pretende abordar as relações entre o significante e a letra, escrita e criação, o que implica recorrer a análise da teoria lacaniana, principalmente a partir do Seminário 20 - Mais Ainda (1993). A respeito deste percurso já assinalamos na seção anterior. Cabe agora fazer alguns encaminhamentos, os quais devem dar visibilidade às questões que a linguagem poderá contribuir para o entendimento das relações entre o significante e a letra nas subjetividades.

A partir de 1974 (Seminário R.S.I. e O sintoma), Lacan introduz algu- 
mas precisões em relação a sua primeira definição da psicose - a psicose é uma não-nodulacão a três; uma nodulação pode existir, mas não a três. É preciso ter um quarto elemento e isso é ter um sintoma - ter um quarto elemento que faz sintoma. Assim, uma nodulação que não é sem sintoma é uma definição de psicose. Para Julien (1999), esta é a subversão do seminário do sintoma - passar do Ter (um sintoma/Freud) ao Ser (um sintoma). Na neurose, temos um sintoma; na psicose, há uma tentativa de ser o sintoma. Lacan, ao referir-se a Joyce (Le Sinthome ou o simptôme), diz que este, pela arte de escrever, conseguiu ser o sintoma (fazer um nome no público). Joyce o sintoma, é o caso de uma psicose sem delírio - uma não-nodulação a três. A loucura seria, assim, a renúncia ao reconhecimento e, Joyce não fez isso. Em Le Sinthome (1976), ao analisar o caso Joyce, Lacan diz que ele é o sintoma puro da escrita, em sua abstração.

A discussão a respeito do sintoma/sinthome, diz respeito à passagem do Ter ao Ser, ou seja: Lacan diz que Ter o sintoma é a neurose e isso já estava em Freud. Nessa dimensão do Ter, o que está em questão é o paido-nome, o pai nomeador, o pai ideal que a histérica sustenta - é ter o quarto elemento/ter um sintoma, o pai-do-nome (nome-do-pai como pai-do-nome). Ser um sintoma é Ser uma personalidade - fazer-se um pai-do-nome). Ser um sõo esta suplência (prefirimos versão) acontece onde não há delírio, mas o significante do nome-do-pai está foracluído. Temos, assim, duas espécies de quarto elemento que impedem o delírio (a desonodulação): ter um sintoma ou ser um sintoma. O psicótico terá que fazer suplência (versão) à ausência do Nome-do-Pai. Por não ter podido "servir-se" adequadamente do pai, ele é um sem-nome (Freire, 2001). Retomando o caso Joyce, Freire diz que este procurou então, como forma de suplência (versão), ser pai de si mesmo.

Temos, pois, três elementos centrais que podem nortear nosso trabalho acerca das relações entre o significante e a letra nas psicoses: o significante do Nome-doPai/Nomes-do-Pai (foraclusão), o sintoma/sinthome (versão possivel ao Nome-do-Pai) e a letra/escrita (uma das possibilidades de versão; o escrever como uma forma de manter o equilíbrio psíquico /Joyce). Nas áreas da clínica e da educação e no trabalho com crianças e adolescenNas áreas da clínica e da educaçáo eno no trilidade de suplência/versão nos toca de perto. Entretanto, não só ela, pois o que está em questão, também, é a de perto. Entretanto, não só ela, pois o que de suplência/versão. Para Julien (Idem), ajudar um psicótico numa participação social não implica se debruçar sobre sua vida privada, sobre o gozo fálico, pois não é este o problema. Para o psicótico, o principal são as imagens das personalidades, já que sua participação social dá-se em função de uma imagem (retorno de Lacan às questões do imaginário? Talvez. Mas, trata-se de outra concepção de imaginário). Assim, em uma leitura literal de Lacan, Julien diz que, no psicótico, ao ocorrer um fracasso de gozo na vida privada (fracasso do gozo fálico), há a necessidade de uma forte participação social. Supondo que tal pressuposição seja correta, a clínica, os estudos da linguagem e a educação têm aí um papel a realizar.

Com base no caso Joyce, Meira (1999) pergunta se as dificuldades de ler e escrever em certas crianças não estariam ligadas a outras escritas. Ainda: se há um impedimento com relação à leitura dessas escritas (dessas marcas), o que a psicanálise pode fazer? O que os estudos de linguagem podem esclarecer? O que a educação pode fazer? Como constituir outras marcas, outras escrituras? Como reinscrever, noutra parte, aquilo que, por questão de estrutura (foraclusão do Nome-do-Pai) faz impedimento?

Allouch, citando Lacan, diz: um ser que pode ler sua marca, isso basta para que ele possa se reinscrever noutra parte além dali onde a gravou. Entretanto, tal reinscrição pressupõe, segundo Lacan, ir além do pai, servindo-se dele (ALLOUCH, 1995) Quando isso não é possível, há que se fazer suplência/versão. Assim, a discussão concernente às relações entre as criançasadolescentes em estruturação e o saber - reinscrição ou constituição de uma suplência/versão, via diversas possibilidades do Nome-do-Pai, além da escrita -, constitui um caminho de investigação a respeito da relação entre o significante e a letra.

Assim, do ponto de vista psicanalítico, educacional e de linguagem, podemos formular as seguintes interrogações:

a) Como se dá a discussão acerca do significante e da letra nos escritos de crianças e adolescentes na escola?

b) Como se dá a discussão acerca do sintoma/sinthome/criação, nos processos de subjetivação desses sujeitos?

c) Como podemos estabelecer uma discussão acerca do Nome-do-Pai/Nomes-do/Pai entrelaçada com esses mesmos processos de subjetivação?

d) Como se dá a discussão acerca das questões de escrita e criação na escola? e) Como podemos pensar esses processos de subjetivação das crianças e adolescentes para além da escola, ou seja, no campo social e cultural?

f) Como se dá a discussão acerca das origens da linguagem na sua relação à letra?

São questões que abrem diversos encaminhamentos para pensarmos os processos de subjetividade, linguagem e criação não como inerentes somente ao campo escolar, mas como processos que fazem parte do campo social e cultural dos sujeitos.

Não procuraremos responder a tais questões, pois são muito amplas e 
necessitariam de outro espaço, para além deste artigo. Entretanto, sua formulação nos permite ter um traçado, um caminho possível para futuras elaborações. Pretendemos, a partir deste momento, no que diz respeito às elaborações. Pretendemos, a partir deste momento, estabelecer algumas reflexões sobre as interrogações acima enunciadas, fundamentalmente no que se refere às origens da linguagem e da escrita.

3.3. O significante e a letra: encaminhamentos para os estudos de linguagem

Lacan, no Seminário 20 - Mais Ainda, ao falar sobre a contingência do significante, diz que há um outro efeito de linguagem, que é a escrita (LACAN, 1993 , p. 63). Temos, assim, a existência do inconsciente pelo escrito; o inconsciente está estruturado como essa linguagem cuja estrutura só se revela pelo escrito (ALLOUCH, 1995, p. 151). O escrito, as letras, constituem os ajuntamentos - as letras são -; elas são tomadas como funcionando como esses ajuntamentos mesmos (grifo nosso) (LACAN, 1993, p. 65). Lacan esses ajuntamentos mesmos (grifo nosso) (LACAN, 19 é estruturado como uma linguagem. Assim, o inconsciente é estruturado como os ajuntamentos de que se trata na teoria dos conjuntos como sendo letras (Idem, p. 66).

Lacan, neste seminário, diz que se trata de tomar a linguagem como aquilo que funciona em suplência, por ausência da única parte do real que não pôde vir a se formar em ser, isto é, a relação sexual (Idem, Ibidem). Para Allouch (1995), o que insiste no inconsciente, é a letra e não o significante, ou seja, o que insiste é o que foi apagado e não o significante que tomou seu lugar. Perguntamo-nos, em vista disso, o que é que insiste, no sujeito psicótico, já que o que deveria advir - algum significante do Nome-doPai , não adveio. $\mathrm{O}$ autor diz que o significante, na psicose, eqüivale a um nome próprio. Assim, o psicótico, ao ter foracluído um significante concernente ao Nome-do-Pai, encontra um pulular de nomes próprios.

Acentuamos que se trata de uma foraclusão localizada, já que o que é foracluído é um significante concernente ao Nome-doPai (não o Pai). Para Allouch (idem), há um laço entre a operação local de foraclusão - que incide sobre um nome - e o pulular de nomes próprios que referimos anteriormente. O "pulular" significa uma cascata de remanejamento de significantes. Tais remanejamentos provocam uma transformação radical do sujeito psicótico com a linguagem.

Devemos ter em vista que, quando o significante do Nome-doPai não se encontra foracluído, há uma particularização do mesmo, uma localização. No sentido da letra - como estrutura essencialmente localizada do significante -, o significante do Nome-doPai é, devido a sua localização, um significante como tal, escrito (Idem).

Na psicose, onde há uma foraclusão do significante do Nome-doPai, não há o nascimento do significante; falta o seu acesso, já que a função do pai é trazer a criança para o registro do significante. Para o autor, o pai faz incluir o significante assemântico - cuja propriedade é não significar nada - e, com isso, justamente, proporciona que possa vir a significar alguma coisa.

Analisamos, anteriormente, que o significante na psicose eqüivale a um nome próprio, a um pulular de nomes próprios. Entretanto, qual a definição de nome próprio quando se vê, nas psicoses, o significante definido como seu equivalente? Para Allouch, responder a esta questão significa tomar o significante como objeto - é a constituição da letra, do escrito. Isto remete às origens do sujeito e da própria linguagem.

O significante primordial que está na origem lógica da linguagem é o Nome-do-Pai. Para saber como funciona o operador Nome-do-Pai, é preciso investigar as origens lógicas da linguagem, ou seja, investigar a concomitância entre o aparecimento da escrita e o surgimento da linguagem. Em outros termos, investigar as relações, na origem lógica da linguagem e do surgimento do sujeito, entre o significante e a letra/escrito. É um encaminhamento possível.

\subsection{As relações entre o significante e a letra: campo da educação}

No que concerne ao campo educacional, nossos interesses incidem sobre as escritas de crianças e adolescentes que freqüentam a escola. É por meio de tais produções que pretendemos cercear o modo como se dá as relações entre o significante e a letra nesses sujeitos com uma estruturação psíquica singular. Nosso intuito ainda, com essas análises que procuram articular o campo da psicanálise ao da linguagem e ao da educação, é estabelecer a escola como um dos lugares possíveis e necessários para o processo de subjetivação dessas crianças e adolescentes. Escola como um lugar social de se estar, onde seja possível que tais sujeitos possam constituir a face pública de suas produções, de modo a conseguir uma organização subjetiva. Conhecemos as dificuldades de tal processo, mas acreditamos que a escola, entre outras possibilidades sociais e culturais, pode contribuir para que esses sujeitos possam ler sua marca, sua produção, para além de onde esta se gravou. Aliás, para muitas destas crianças, a escola será o único lugar possível a que eles terão acesso. A escola, aqui, se constitui então como um locus previlegiado de trabalho com esses sujeitos. 
Assim, nosso principal interesse, no que concerne às questões de educação, é ter uma compreensão da função da emergência e do modo singular pelo qual as formas se produzem no interior da escrita dos sujeitos, desembocando em um processo inscrito em uma ordem do nãoinventariável, do singular, da criação. É por esse motivo que recorremos ao campo da psicanálise e da linguagem.

A singularidade da produção do sujeito é o principal aspecto a ser levado em consideração. A metodologia subordina-se a esta singularidade. As escritas que são nosso objeto de análise - palavras, sílabas, fonemas, letras - não são somente letras escritas no papel, mas também, letras inscritas no corpo, como um livro de carne, no qual se inscrevem os significantes da demanda e do desejo do Outro (Yankelevich, 1999, p. 135).

\section{ENCAMINHAMENTOS}

Apresentamos, nas seções anteriores, algumas questões acerca do significante e da letra nas psicoses. Tal problematização teve o intuito de rever a discussão sobre o significante e a letra, tanto a partir do ponto de vista da linguagem, como das articulações dessa com a psicanálise. Essa explanação não esgota, em absoluto, a discussão em torno do significante e da letra; apenas ressitua, em outros termos, algumas controvérsias, principalmente as que concernem ao papel do significante da letra para além do discurso psicótico. Tal percurso nos auxilia a refletir acerca das subjetividades escolares, principalmente aquelas que dizem respeito a uma estruturação singular. Enfim, é um modo de entendermos a produção de subjetividade sem a alcunha de uma nominação restritiva à sua constituição.

\section{BIBLIOGRAFIA}

ALLOUCH, Jean. Letra a letra: transcrever, traduzir, transliterar. Rio de janeiro: Campo Matêmico, 1995.

BIRMAN, Joel. Sobre a psicose. Rio de Janeiro: Contracapa livraria, 1999. BRANCION, Marie-Magdeleine Chatel. Haverá um irredutível do sintoma? In: Letra Freudiana - Do sintoma ao sinthoma. Rio de Janeiro: Ed. Revinter, n. 17/18, 1996.
FREIRE, Ana Beatriz. Considerações sobre a letra: a psicose em questão. In: Revista Psicologia: Reflexão e Crítica. Vol. 1, n. 1. Porto Alegre: CPG Psicologia/UFRGS, 1986.

FREIRE, Ana Beatriz. Prova de realidade e/ou rejeição. In: BIRMAN, Joel. Sobre a Psicose. Rio de Janeiro: Contracapa livraria, 1999.

FREIRE, Marcelo Muniz. A escritura psicótica. Rio de Janeiro: Companhia de freud, 2001.

JULIEN, Philippe. As psicoses. Rio de Janeiro: Companhia de Freud, 1999.

EDITORIAL - LE DISCOURS PSYCHANALYTIQUE. In: Le discours $P_{s y-}$ chanalytique - Des Folies: questions récents sur les psychoses. Paris: Depôt légal, $1984-$ n. 10.

LAIA, Sergio. Os escritos fora de si: Joyce, Lacan e a Loucura. Belo Horizonte: Autêntica, 2001.

LETRA FREUDIANA. Do Sintoma ao Sinthoma. - Ano XV n.17/18. Rio de Janeiro: Contracapa Livraria, 1996.

. Do Pai: o limite em psicanálise - Ano XVI n. 21. Rio de Janeiro: Contracapa Livraria, 1997.

A Jornada de Ulisses - ano XX n. 28. Rio de Janeiro: Contracapa Livraria, 2001.

- A criança e o saber - Ano XVII n.23. Rio de janeiro: contracapa livraria, 1999.

LACAN, Jacques. Le Séminaire, Livre XX: Encore. Paris: Seuil, 1975.

LACAN, Jacques. Le Séminaire 1974-5, livre XXII: RSI, Ornicar?, n. 5, 1975 Le Séminaire 1975-6, livre XXIII: Le sinthome, Ornicar?, n.8, 1976.

. O seminário - Livro 3: As psicoses (1955-56). Rio de Janeiro: Zahar, 1988.

. O Seminário - Livro 20: Mais, ainda. Rio de Janeiro: Zahar Ed., 1993.

YANKELEVICH, Dora. O corpo e a letra: o saber em transferência. In: Le-

tra Freudiana - A criança e o Saber - Ano XVII n. 23. Rio de Janeiro: Contracapa Livraria, 1999.

MEIRA, Yolanda Mourão. A criança e a escrita. In: Letra Freudiana - A crianca e o Saber. Rio de janeiro: Ed. RevinteR, ano XVII, n.23, 1999.

PAOLI, Cynthia. “Tu és teu sinthome”. In: Revista Tempo Psicanalitico. V. 33, Rio de Janeiro, 2001.

PORGE, Erick. Os nomes do pai em Jacques Lacan. Rio de janeiro: Companhia de Freud, 1998.

ROUDINESCO, Elisabeth e PLON, Michel. Dicionário de Psicanálise. Rio de Janeiro: Jorge Zahar Ed., 1998.

SANTOS, Tania Coelho. As estruturas freudianas da psicose e sua reinvenção lacaniana. In: BIRMAN, Joel (Org.). Sobre a Psicose. Rio de Janeiro: Contra Capa Livraria, 1999. 
SOLER, Colette. A Psicanálise na civilização. Rio de Janeiro: Contra Capa Livraria, 1998.

SCHÄFFER, Margareth et al. O processo de construção da subjetividade: marcas Lingüísticas no discurso do neurótico e do psicótico. Relatório Técnico de pesquisa-CNPq, 1998.

- A constituiçãa do sujeito: a metáfora na neurose e na psicose. Relatório Técnico de Pesquisa - CNPq, 2000.

. Constituição da subjetividade: um estudo da negação no discurso do neurótico e do psicótico. Letras de Hoje. Porto Alegre. V.34, nº 2, junho de 1999.

SCHÄFFER, Margareth; FLORES, Valdir do Nascimento; BARBISAN, Leci (ORG.). Aventuras do sentido: psicanálise e Linguística. Porto Alegre: EDIPUC, 2002. . et alli. A denegação na neurose e na psicose. In: Aventuras do sentido. Porto Alegre: EDIPUCRS, 2002. .et alli. A constituição da subjetividade: a questão do significante. In: Aventuras do sentido. Porto Alegre: EDIPUCRS, 2002. .et alli. A metáfora e a constituição da subjetividade na psicose. In: Os estudos enunciativos: a diversidade de um campo. Revista Organon 32/33, 2002.

- A demanda escolar à clínica: quando o não-aprender passa a ser o nome (do aluno). In. Psicologia e Educação: Multiversos Sentidos, olhares e experiências. Porto Alegre: Editora da UFRGS, 2003. . A produção da escrita na escola de crianças e adolescentes com ou sem estruturação psicótica. In: Revista FAPA: Porto Alegre, 2004 . Invenção e Criação. In: Revista Educação e Realidade. Vol. 28, n.2 e 3. 2004. 